\title{
Hydrologic Variations and Stochastic Modeling of Runoff in Zoige Wetland in the Eastern Tibetan Plateau
}

\author{
Guanghua Qin, ${ }^{1}$ Hongxia Li, ${ }^{1}$ Zejiang Zhou, ${ }^{2}$ Kechao Song, ${ }^{1}$ and Li Zhang ${ }^{3}$ \\ ${ }^{1}$ State Key Laboratory of Hydraulics and Mountain River Engineering, Sichuan University, Chengdu 610065, China \\ ${ }^{2}$ Guangxi Water and Power Design Institute, Nanning 53000, China \\ ${ }^{3}$ Everglades Wetland Research Park, Florida Gulf Coast University, Naples, FL 34112, USA
}

Correspondence should be addressed to Hongxia Li; hx_li406@126.com

Received 18 December 2014; Accepted 10 February 2015

Academic Editor: Yongqiang Zhang

Copyright (C) 2015 Guanghua Qin et al. This is an open access article distributed under the Creative Commons Attribution License, which permits unrestricted use, distribution, and reproduction in any medium, provided the original work is properly cited.

\begin{abstract}
Hydrological time series data (1988-2008) of the Hei River, the main water source to Zoige wetland in the Eastern Tibetan Plateau, were investigated. Results showed that the runoff distribution of Hei River varies with the relative change in amplitude $\left(C_{m}=15.9\right)$ and the absolute change in amplitude $\left(\Delta Q=37.1 \mathrm{~m}^{3} / \mathrm{s}\right)$ during the year. There was a significant decreasing trend since 1988 with annual runoff of $20.0 \mathrm{~m}^{3} / \mathrm{s}(1988-1994), 19.0 \mathrm{~m}^{3} / \mathrm{s}$ (1995-2000), and $15.2 \mathrm{~m}^{3} / \mathrm{s}$ (2001-2008). There were double peaks in runoff during the water year: the highest peak in the period of 1988-2000 occurred in July while in the period of 2001-2008 it occurred in October. Shifting peak flow means less water quantity in wetland during growing season. Nearest neighbor bootstrapping regressive method was used to predict daily runoff of the Hei River. Model results show that it was fitted with $94.23 \%$ of $R^{2}$ for daily time series, which can provide a basis for the development and utilization of regional water resources.
\end{abstract}

\section{Introduction}

The Zoige wetland contains the largest high altitude wetland ecosystem in the world, which is over $5,000 \mathrm{~km}^{2}$ and $\sim 3500 \mathrm{~m}$ above sea level [1]. The Zoige wetland ecosystem provides at least $30 \%$ of the water flowing into the upper reaches of the Yellow River (e.g., [2, 3]). However, the area of the wetland has been recently lost by desertification which is increasing at a rate of more than $10 \%$ per year [4-6]. The recent degradation of Zoige Peatland was often attributed to both the ditching drainage and climate change [3]. With the global warming becoming stronger, it will therefore become increasingly necessary to understand hydrologic processes to prevent further degradation (e.g., $[7,8])$.

Hydrologic processes such as hydroperiod, flow duration and variability, and flood recession significantly impact the dynamics of wetland ecosystems $[9,10]$. Times series approach to model hydrologic process and dynamics in river and stream has been well documented (e.g., [11-14]), since Thomas and Fiering [15] and Yevjevich [16] revealed that the hydrological phenomenon shows objective dependency on time domain and was described by the Markov model. Shinohara et al. [17] used a stochastic approach to explore the impact of climate change on runoff from a midlatitude mountainous catchment in central Japan. Verma et al. [13] explore the seasonal changes of soil moisture influenced by daily rainfall in New South Wales Australia using a stochastic model.

More recently, a couple of studies with stochastic model approaches have been published such as spatial and temporal distribution stochastic model in Raoli River basin in Sanjiang Plain and the hydrologic trend stochastic model in Wuyuer River in Zhalong wetland, Northeast China [18]. However, the stochastic models with hydrological time series used in alpine region are probably different from low elevation areas. So it is necessary to develop a stochastic model for runoff prediction in Zoige wetland in the Eastern Tibetan Plateau.

The objective of this study is to explore the Hei River runoff variations annually, monthly, and daily for a long term (1988-2008) and to understand hydrologic process during the wet and dry seasons and how the changes impact ecosystem of Zoige wetland in the Eastern Tibetan Plateau with climate 


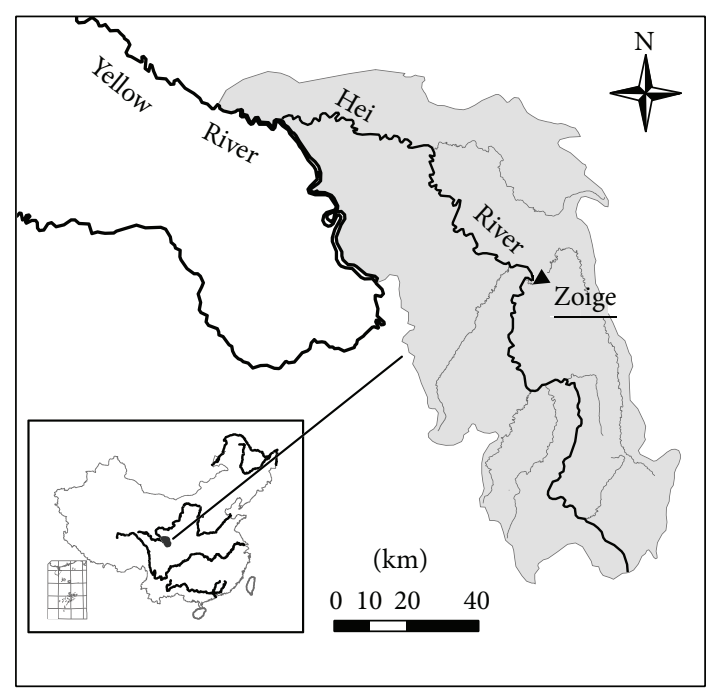

FIgURE 1: Location of the study area.

changes. Nearest neighbor bootstrapping regressive method was used to model the variations of daily runoff in order to provide a basis for the development and utilization of regional water resources.

\section{Data and Methods}

2.1. Data. Hei River is located in the Eastern Tibetan Plateau where wetlands are distributed widely. As the largest river in Zoige wetland, Hei River is the major tributary of the upstream of the Yellow River (Figure 1) and it flows from the south to the north and turns to the northwest at Zoige county town and flows finally to the Yellow River [19]. The length of the Hei River is $455.9 \mathrm{~km}$, with an average gradient of $0.2 \%$ and the drainage area of $7608 \mathrm{~km}^{2}$ [20]. There are many small lakes, which mostly are small swamps and oxbow lakes in the watershed.

We collected daily runoff, temperature, and precipitation during 1988 to 2008 at the Zoige hydrologic station in the Hei River middle reaches. The moving average method, MannKendall testing method [21], and self-correlation diagram were used to analyze the trend and the dependency of the annual runoff, and homogeneous degree and variation and self-correlation diagram were used to analyze the distribution of the monthly runoff.

2.2. Nearest Neighbor Bootstrapping Regressive Model. Nearest neighbor bootstrapping regressive model (NNBR) is data driven and nonparametric, with potential priority, and needs no assumption in the form of dependence and probability distribution, as well as no estimate of many parameters [2224].

Generally, there exists correlation between hydrology phenomena along timescale. Thus, to an extent, $X_{t}$ depends on the historical daily runoff $Q_{t-1}, Q_{t-2}, \ldots, Q_{t-P}$. Given $D_{t}=$ $\left(Q_{t-1}, Q_{t-2}, \ldots, Q_{t-P}\right)$, it is named as eigenvector of the daily runoff series. Then, $X_{t}=\left(Q_{t}, Q_{t+1}, \ldots, Q_{t+m-1}\right)(t=P+1, P+$ $2, \ldots, n-m+1)$ can be defined as the succeeding value of $D_{t}$.

Among $D_{t}(t=P+1, P+2, \ldots, n)$ which are constituted by $\left\{Q_{t}\right\}_{n}$, there must be some nearest neighbor eigenvectors to current eigenvector $D_{i}$. Suppose the number of nearest neighbor eigenvectors is $K$, and it is represented by $D_{1(i)}, D_{2(i)}, \ldots, D_{K(i)} . X_{1(i)}, X_{2(i)}, \ldots, X_{K(i)}$ must be the succeeding values of each corresponding eigenvector. The nearest neighbor is judged by the difference between $D_{i}$ and $D_{t}$, which is defined as

$$
r_{t(i)}=\left(\sum_{j=1}^{P}\left(d_{i j}-d_{t j}\right)^{2}\right)^{1 / 2}
$$

where $r_{t(i)}$ represents the difference between $D_{i}$ and $D_{t}, d_{i j}$ and $d_{t j}$ are number $j$ variable of $D_{i}$ and $D_{t}$, respectively, and $P$ is the dimension of eigenvector. Then, $r_{j(i)}(j=1,2, \ldots, K)$ is denoted by the difference between $D_{j(i)}$ and $D_{i}$, and it should be mentioned that $r_{1(i)}<r_{2(i)}<\cdots<r_{K(i)}$ (the number $j$ is ordered according to the value of $\left.r_{j(i)}\right)$. The less $r_{j(i)}$ is, the nearer $D_{i}$ and $D_{j(i)}$ will be, and $X_{i}$ is more similar to $X_{j(i)}$. Let $G_{j(i)}$ be the nearest neighbor bootstrapping weight of $X_{j(i)}$, which shows similarity between $X_{i}$ and $X_{j(i)}$. Obviously, $G_{j(i)}$ is related to $r_{j(i)}$.

As discussed above, the relative value of number $i$ variable of number $j$ nearest neighbor succeeding vector $X_{j(i)}$ is known. The succeeding vector $X_{i}$ can be obtained through multiplying predicted daily runoff $G_{j(i)}$. Thus, the ultimate formula of NNBR model can be given as

$$
X_{i}=\sum_{j=1}^{K} G_{j(i)} X_{j(i)} .
$$

NNBR model is confirmed when the number of nearest neighbor $K$, the dimension of eigenvector $P$, and the nearest neighbor bootstrapping weight $G_{j(i)}$ are estimated.

Generally, $K=$ int $\sqrt{n-P}$ is given. If $P \geq 2$, the dimension of eigenvector $P$ can be estimated by runoff autocorrelation graph or partial-correlation graph.

There are a number of methods to estimate bootstrapping weight $G_{j(i)}$. When estimating, first of all, its restraint condition must be satisfied, and then bootstrapping weight $G_{j(i)}$ should be related to $r_{j(i)}$, and the bootstrapping weight function should equal one (3). As the number $j$ is ordered according to the value of $r_{j(i)}$, in this paper, the following formula is adopted:

$$
\begin{gathered}
\sum_{j=1}^{K} G_{j(i)}=1, \\
G_{j(i)}=\frac{(1 / j)}{\sum_{L=1}^{K} 1 / L} \quad(j=1,2, \ldots, K) .
\end{gathered}
$$

When $K$ is confirmed, we can only calculate $G_{j(i)}$ once.

We used the following qualification rate $(\mathrm{QR})$ and coefficient of determination $R^{2}$ to estimate model fits for the calibration and validation. In this study, if the prediction of 


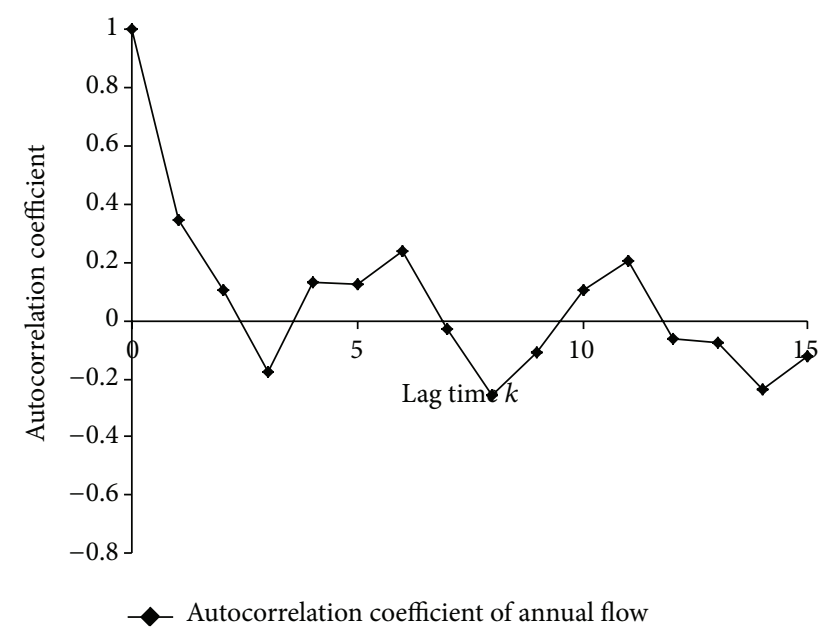

FIGURE 2: Autocorrelation coefficient and lag time of the annual runoff.

relative error was less than $20 \%$, thus the model was assumed to be qualified:

$$
\mathrm{QR}=\frac{n}{m} \times 100 \%,
$$

where $n$ is the number of qualified predictions and $m$ represents the totality.

\section{Results and Discussions}

According to the runoff observation data from 1988 to 2008 (except 1998) at Zoige hydrologic station, the average annual runoff is $20.40 \pm 1.70 \mathrm{~m}^{3} / \mathrm{s}$, the average annual runoff depth is $161.0 \pm 13.37 \mathrm{~mm}$, and the average annual discharge is $(6.44 \pm$ $0.53) \times 10^{8} \mathrm{~m}^{3}$, respectively.

The degree of dispersion of annual runoff time series is too large with the variation coefficient $C_{v}=0.37$ and skewness coefficient $C_{s}=0.2$. It is because Hei River belongs to the river with the rain-snow and ice fusion. Discharge of runoff depends largely on the precipitation variation and snowmelt [25]. However, because average annual runoff of the area itself is small, interannual variation of runoff is relatively small, which led to weak dependence of the annual runoff series (Figure 2).

During the period of 1988 2008, the largest annual flow occurred in 1999 (up to $32.6 \mathrm{~m}^{3} / \mathrm{s}$ ), while the lowest annual runoff occurred in 2002, only $8.3 \mathrm{~m}^{3} / \mathrm{s}$, respectively. Hei River runoff decreasing trend is remarkable since 1988 (Table 1 and Figure 3). The higher temperature and less precipitation led to the decreasing trend of runoff (Figures 4 and 5). From 1988 to 1999 is the abundant water period; from 2000 to date is the drier period. According to the observation data, the average annual flow from 1988 to 1994 is $27.0 \pm$ $0.75 \mathrm{~m}^{3} / \mathrm{s}$ and the average annual flow has decreased to $19.0 \pm$ $1.24 \mathrm{~m}^{3} / \mathrm{s}$ during 1995 2000 and $15.2 \pm 0.74 \mathrm{~m}^{3} / \mathrm{s}$ during 2001 2008, respectively (Figure 3 ). The trend of decreased annual runoff impacted ecosystems of Zoige wetland and partly contributed to wetland degradation with habitats loss.

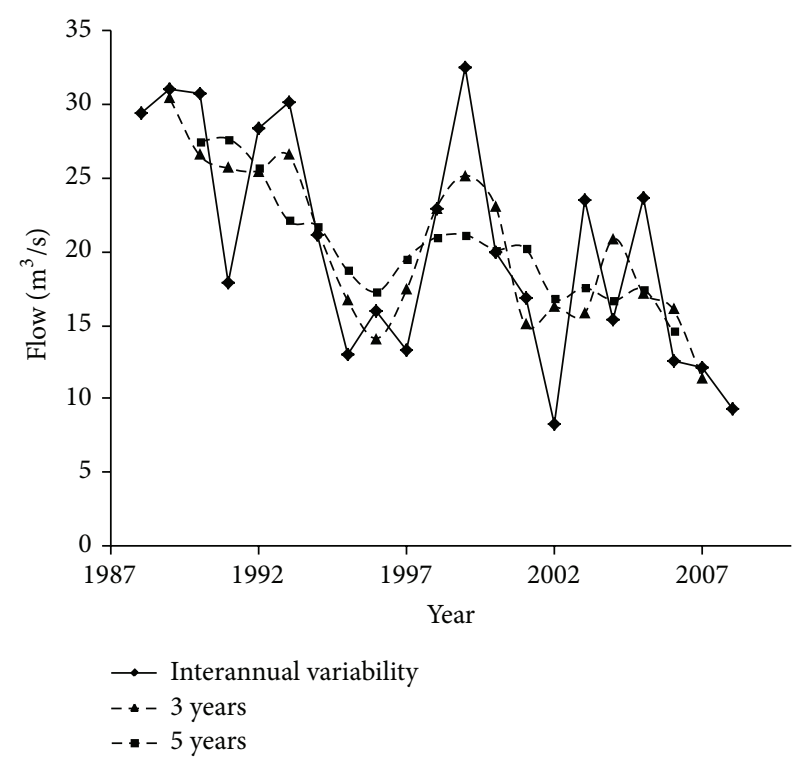

FIgURE 3: Trend of the variation of annual runoff.

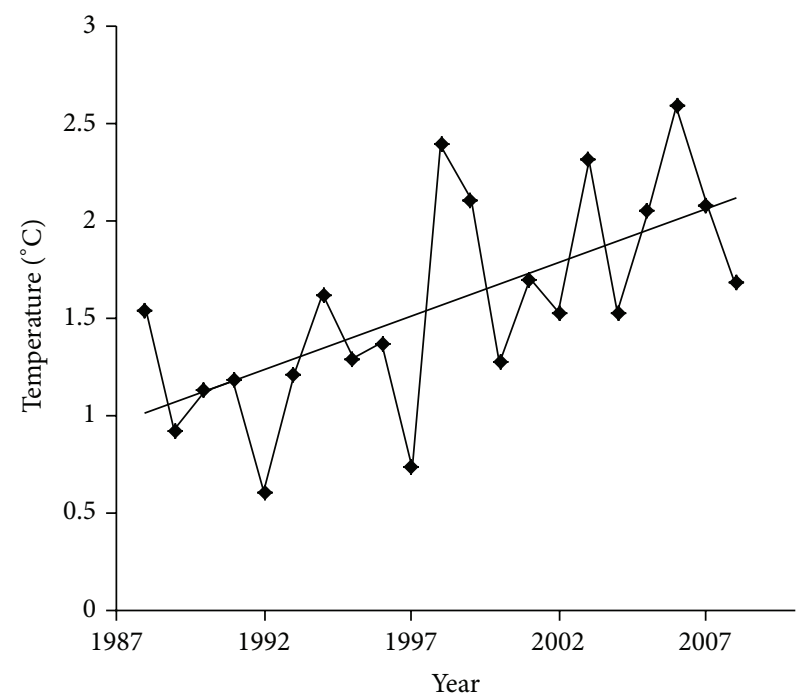

FIgURE 4: Trend of the variation of annual temperature.

TABLE 1: Tendency of the runoff series of years by Mann-Kendall statistical test.

\begin{tabular}{lcccc}
\hline $\begin{array}{l}\text { Test } \\
\text { statistic } U\end{array}$ & $\begin{array}{c}\text { Significance } \\
\alpha\end{array}$ & $\begin{array}{c}\text { Critical } \\
\text { value } U_{\alpha / 2}\end{array}$ & $\begin{array}{c}\text { Judge } \\
\text { result }\end{array}$ & Tendency \\
\hline-2.92 & 0.05 & 1.96 & $|U|>U_{\alpha / 2}$ & $\begin{array}{c}\text { Significant } \\
\text { decrease }\end{array}$ \\
\hline
\end{tabular}

The results of this study are consistent with previous findings of degradation of the wetland ( $-13.08 \%$ for swamp, $-6.31 \%$ for river, and $-20.24 \%$ for lake) from 1987 to 2004 that associated significantly with changes in hydrological processes [3]. Due to decreasing annual runoff, it resulted in the fact that overflow of water could not reach adjacent wetlands and led to wetland function loss [3]. 


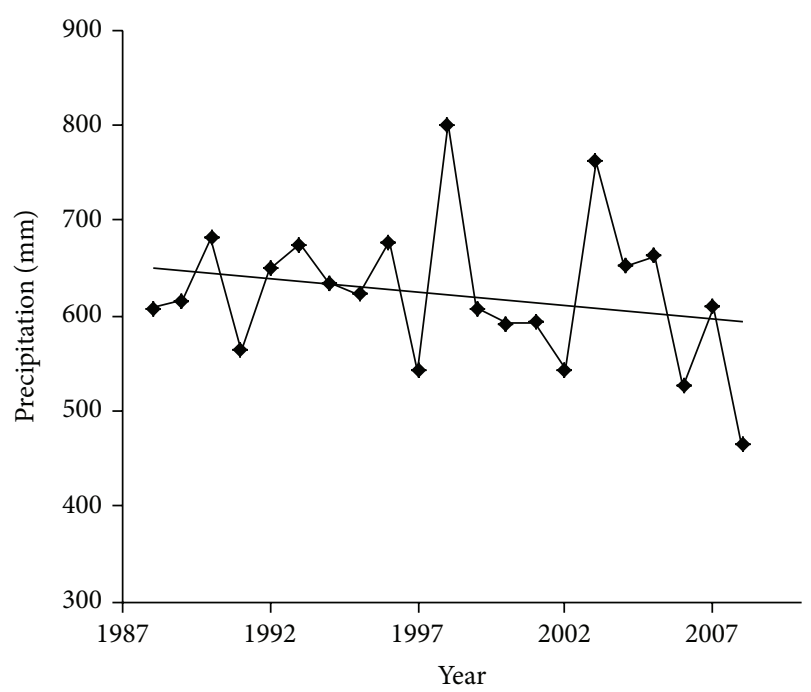

Figure 5: Trend of the variation of annual precipitation.

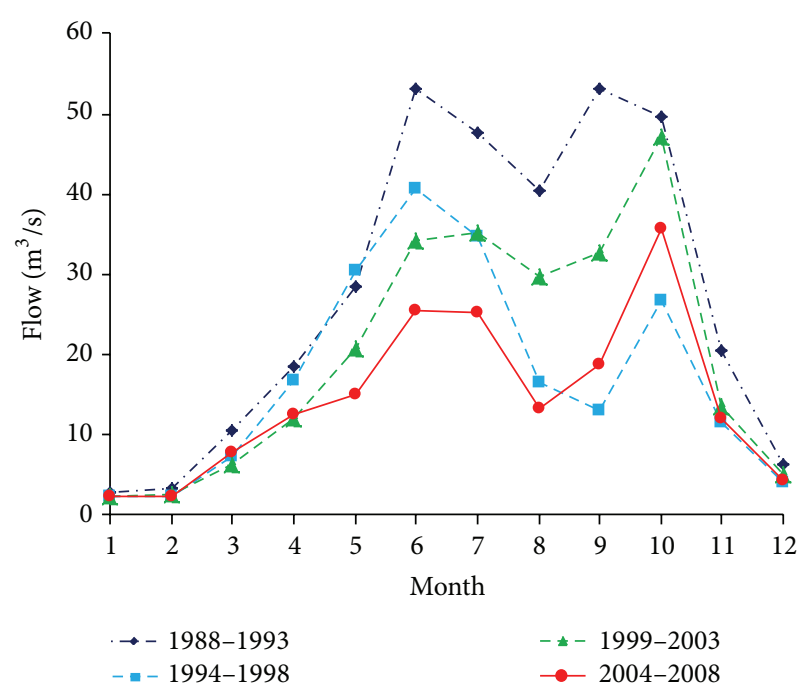

FIGURE 6: Monthly runoff distribution during 1988 to 2008 with a 4 -year increment.

The monthly runoff distribution during the year is uneven (Figure 6), and the relative change amplitude $C_{m}$ is 15.9 and absolute change amplitude is $37.1 \pm 4.04 \mathrm{~m}^{3} / \mathrm{s}$. Peak runoff mainly concentrated in the months $5-10$. This river is supplied at the same time by two ways: precipitation and snow and ice ablation. In winter, the runoff is very small because the low temperature makes the surface frozen. With the spring coming, it becomes swarm, but the temperature is still very low, and the wetland is covered by ice and snow, while in summer when the temperature is higher, peak flow occurred by precipitation, snowmelt, and the runoff of the river in summer. Pulsing flooding water during growing season made high net primary production from wetland plant communities [10, 26].

Dry season (December to February) contributes only $4.4 \%$ of discharges for all the year, while wet season
TABLE 2: Daily runoff prediction for 2008 of Hei River using NNBR model.

\begin{tabular}{cccc}
\hline NNBR model & Mean of relative error (\%) & QR (\%) & $R^{2}$ \\
\hline 5.61 & 97.50 & 0.98 \\
\hline
\end{tabular}

(May to October) contributes $82.8 \%$ of discharges for all the year, respectively. The nonflood season (November to next April) contributes $17.2 \%$ of discharge for all the year (Figures 5 and 6). It may be because the precipitation's rapid decrease after July leads to the runoff's decrease, and the air temperature is still higher; it has led higher evaporation in August and September and lower in October. The highest peak in the period of 1988-1994 and 1995-2000 occurred in July while in the period of 2001-2008 the highest peak occurred in October (Figure 6). Shifting peak flow means less water quantity in wetland during growing season, which significantly impacts plant communities and also biogeochemical process [27]. The restoration approach used in Zoige wetland resulted in one peat-mining site being filled with water and aquatic vegetation with increased water levels up to $26-50 \mathrm{~cm}$ higher than previously recorded in canals and shallow water canal, respectively. Pioneering vegetation including Eleocharis Horsetail (Equisetum, Eleocharis) and Halerpestes (Halerpestes tricuspis) colonized in the restored sites [3]. The similar hydrologic function study was presented from peat wetlands in Canada where the impact of a change in hydrological function from transmitting to contributing on aquatic chemistry may depend on the residence time of water in the wetland. Shifting peak flow also contributed a short residence time in the wetland to not fully develop characteristic chemical traits of wetland ground water [28]. In general, natural- and human-induced factors may produce gradual and instantaneous trends and shifts (jumps) in hydroclimatic series. For example, the historical shifts in snowmelts suggested that an increase in global and regional temperature affected the discharge from a midlatitude mountain area of central Japan by using a simplified hydrological model and associated stochastic treatments [17, 29]. The occurrence of trends and shifts in hydrologic time series and the ensuing effects on water resources, the environment, and society still are concerned (e.g., [17]).

Through primary selection of the model parameters, trial and error, it determines that $P=2$, nearest neighbor number $K=33$. Then daily runoff of 1988 2007 is used to constitute the feature vector $D_{t}$, which is used to predict daily runoff of the year 2008. The QR is $97.50 \%$ and the $R^{2}$ is 0.98 (Table 2 and Figure 7) in validation phase owing to NNBR model's superiority.

Because NNBR model is data driven and nonparametric, it avoids the uncertainty of parameter and the problem of model choice which is different from other models based on the traditional prediction patterns of "assume-calibrationvalidation." So it was widely used to predict the hydrological series, such as the annual runoff of the Yangtze River in the upper reaches [30]. However, NNBR, the same as other models, would make no sense when the future motion trail of the series is out of the law obtained by its historical data. 


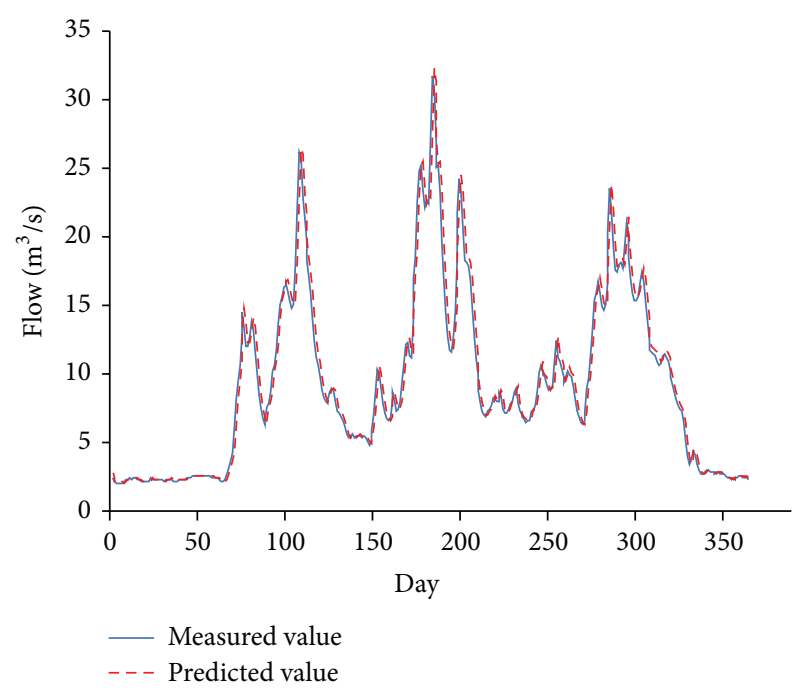

FIGURE 7: Daily runoff prediction for 2008 of Hei River using NNBR mode.

\section{Conclusions}

The annual runoff of Hei River decreased from $27.0 \mathrm{~m}^{3} / \mathrm{s}$ (1988 1994) to $15.2 \mathrm{~m}^{3} / \mathrm{s}$ (2001 2008). The monthly runoff distribution during the year is uneven, and the relative change amplitude $C_{m}$ is 15.9; absolute change amplitude is $37.1 \mathrm{~m}^{3} / \mathrm{s}$. The maximum value of runoff appeared in July in 1988 to 2000 and shifted to October after 2000, which may be because of the precipitation's rapid decrease after July leading to the runoff's decrease, and the temperature is still high; evaporation force is strong in August and September while October evaporation is reduced, so the maximum appears.

A stochastic model and modeling schemes were developed for simulation of hydrologic processes of Hei River. Daily runoff modeling with NNBR model during 2008 has good fits with $97.5 \%$ which is probably more suitable than liner regressive model especially when the time series has no obviously short-dependency.

\section{Conflict of Interests}

The authors declare that there is no conflict of interests regarding the publication of this paper.

\section{Acknowledgments}

This present research is supported by the National Key Basic Research Program of China (973 Program, no. 2013CB036401) and National Natural Science Foundation of China (no. 51209152).

\section{References}

[1] X. Chai and S. Jin, "The types of Zoige Alpine Marsh and its development," Acta Geographica Sinica, vol. 29, pp. 219-240, 1963.
[2] G. Y. Sun, W. F. Zheng, J. Luo, and F. M. Yang, "A study of ecological environment and rational exploration of mires in the Zoige Plateau," Journal of National Resources, vol. 2, no. 4, pp. 359-368, 1987.

[3] X. Zhang, H. Liu, and Z. Xing, "Challenges and solutions for sustainable land use in ruoergai-the highest altitude peatland in Qinhai-Tibetan Plateau, China," Energy Procedia, vol. 5, pp. 1019-1025, 2011.

[4] B. Junhong, O. Hua, C. Baoshan, W. Qinggai, and C. Hui, "Changes in landscape pattern of alpine wetlands on the Zoige Plateau in the past four decades," Acta Ecologica Sinica, vol. 28, no. 5, pp. 2245-2252, 2008.

[5] H. Chen, N. Wu, Y. Gao, Y. Wang, P. Luo, and J. Tian, "Spatial variations on methane emissions from Zoige alpine wetlands of Southwest China," Science of the Total Environment, vol. 407, no. 3, pp. 1097-1104, 2009.

[6] S. Xiang, R. Guo, N. Wu, and S. Sun, "Current status and future prospects of Zoige Marsh in Eastern Qinghai-Tibet Plateau," Ecological Engineering, vol. 35, no. 4, pp. 553-562, 2009.

[7] M. Schumann, N. Thevs, and H. Joosten, "Extent and degradation of peatlands on the Ruoergai Plateau (Tibet, China) assessed by remote sensing," in After Wise Use-The Future of Peatlands, Proceedings of the 13th International Peat Congress: Pristine Mire Landscape, pp. 77-80, International Peat Society, 2008.

[8] X. Zhang, H. Liu, C. Baker, and S. Graham, "Restoration approaches used for degraded peatlands in Ruoergai (Zoige), Tibetan Plateau, China, for sustainable land management," Ecological Engineering, vol. 38, no. 1, pp. 86-92, 2012.

[9] W. J. Junk and K. M. Wantzen, "The flood pulse concept: new aspects, approaches and applications-an update," in Proceedings of the 2nd International Symposium on the Management of Large Rivers for Fisheries, R. L. Welcomme and T. Petr, Eds., vol. 2 of RAP Publication 2004/17, pp. 117-140, Food and Agriculture Organization of the United Nations \& Mekong River Commission, FAO Regional Office for Asia and the Pacific, Bangkok, Thailand, 2004.

[10] W. J. Mitsch and J. G. Gosselink, Wetlands, John Wiley \& Sons, New York, NY, USA, 4th edition, 2007.

[11] D. Machiwal and M. K. Jha, Hydrologic Time Series Analysis: Theory and Practice, Capital Publishing, 2012.

[12] T. A. Ula and A. A. Smadi, "Periodic stationarity conditions for periodic autoregressive moving average processes as eigenvalue problems," Water Resources Research, vol. 33, no. 8, pp. 19291934, 1997.

[13] P. Verma, J. Yeates, and E. Daly, "A stochastic model describing the impact of daily rainfall depth distribution on the soil water balance," Advances in Water Resources, vol. 34, no. 8, pp. 10391048, 2011.

[14] F. Worrall and T. P. Burt, "A univariate model of river water nitrate time series," Journal of Hydrology, vol. 214, no. 1-4, pp. 74-90, 1999.

[15] H. A. Thomas and M. B. Fiering, "Mathematical synthesis of stream-flow sequences for the analysis of river basin by simulation," in Design of Water Resources Systems, P. J. Purcell, Ed., pp. 459-493, Harvard University Press, Cambridge, Mass, USA, 1962.

[16] V. Yevjevich, Fluctuations of Wet and Dry Years (Hydrology Paper1), Colorado State University, Fort Collins, Colo, USA, 1963. 
[17] Y. Shinohara, T. Kumagai, K. Otsuki, A. Kume, and N. Wada, "Impact of climate change on runoff from a mid-latitude mountainous catchment in central Japan," Hydrological Processes, vol. 23, no. 10, pp. 1418-1429, 2009.

[18] X. X. Luo, Study on the wetland water system in the Naoli River watershed in the Sanjiang plain [Ph.D. thesis], Northeast Institute of Geography and Agroecology, Chinese Academy of Sciences, 2002.

[19] S. F. Zhang, S. F. Jia, C. M. Liu et al., "Water cycle change law of the headwater of the yellow river and its impact," Science in China E, vol. 34, pp. 117-125, 2004.

[20] S. Jiang, The study of hydrologic characteristic of the alpine wetland rivers in northwest of Sichuan [Ph.D. thesis], Sichuan University, 2006.

[21] K. H. Hamed, "Trend detection in hydrologic data: the MannKendall trend test under the scaling hypothesis," Journal of Hydrology, vol. 349, no. 3-4, pp. 350-363, 2008.

[22] U. Lall and A. Sharma, "A nearest neighbor bootstrap for resampling hydrologic time series," Water Resources Research, vol. 32, no. 3, pp. 679-693, 1996.

[23] W. Wang, P. Yuan, and J. Ding, "Application of nearest neighbor bootstrap regressive model in prediction of water environment," China Environmental Science, vol. 21, no. 4, pp. 367-370, 2001.

[24] P. Yuan, W. Wang, and J. Ding, "Nonparametric perturbing nearest neighbor bootstrapping model for simulation of flood time series," Journal of Sichuan University (Engineering Science Edition), vol. 32, no. 1, pp. 82-86, 2000.

[25] Q. Tang, Y. Qu, and Y. Zhou, The Utilization of Hydrology and Water Resources in Arid Areas of China, Science Press, Beijing, China, 1992.

[26] W. J. Junk, P. B. Bayley, and R. E. Sparks, “The flood pulse concept in river-floodplain systems," in Proceedings of the International Large Rivers Symposium, D. P. Dodge, Ed., vol. 106, pp. 110-127, Canadian Special Publication of Fisheries and Aquatic Sciences, 1989.

[27] K. R. Reddy and R. D. DeLaune, Biogeochemistry of Wetlands: Science and Applications, CRC Press, 2008.

[28] C. Spence, X. J. Guan, and R. Phillips, "The hydrological functions of a boreal wetland," Wetlands, vol. 31, no. 1, pp. 75-85, 2011.

[29] N. Wada, K. Kawada, R. Kawamura, K. Aoki, and A. Kume, "Increasing winter runoff in a middle-latitude mountain area of central Japan," Journal of the Meteorological Society of Japan, vol. 82, no. 6, pp. 1589-1597, 2004.

[30] W. Wang, H. Xiang, and J. Ding, "Predication of hydrology and water resources with nearest neighbor bootstrapping regressive model," International Journal Hydroelectric Energy, vol. 19, no. 2, pp. 8-10, 2001. 

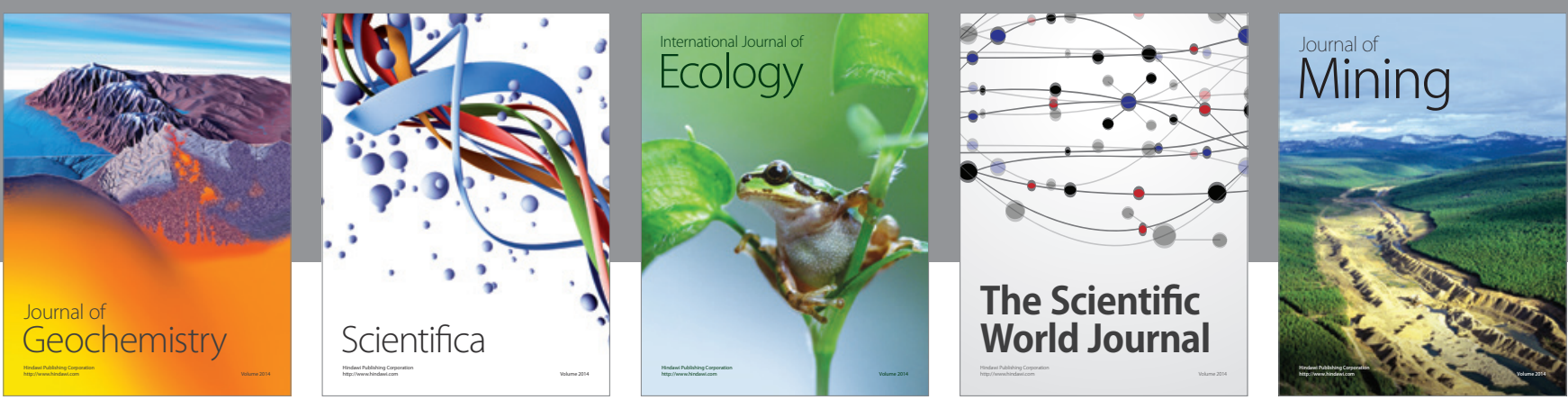

The Scientific World Journal
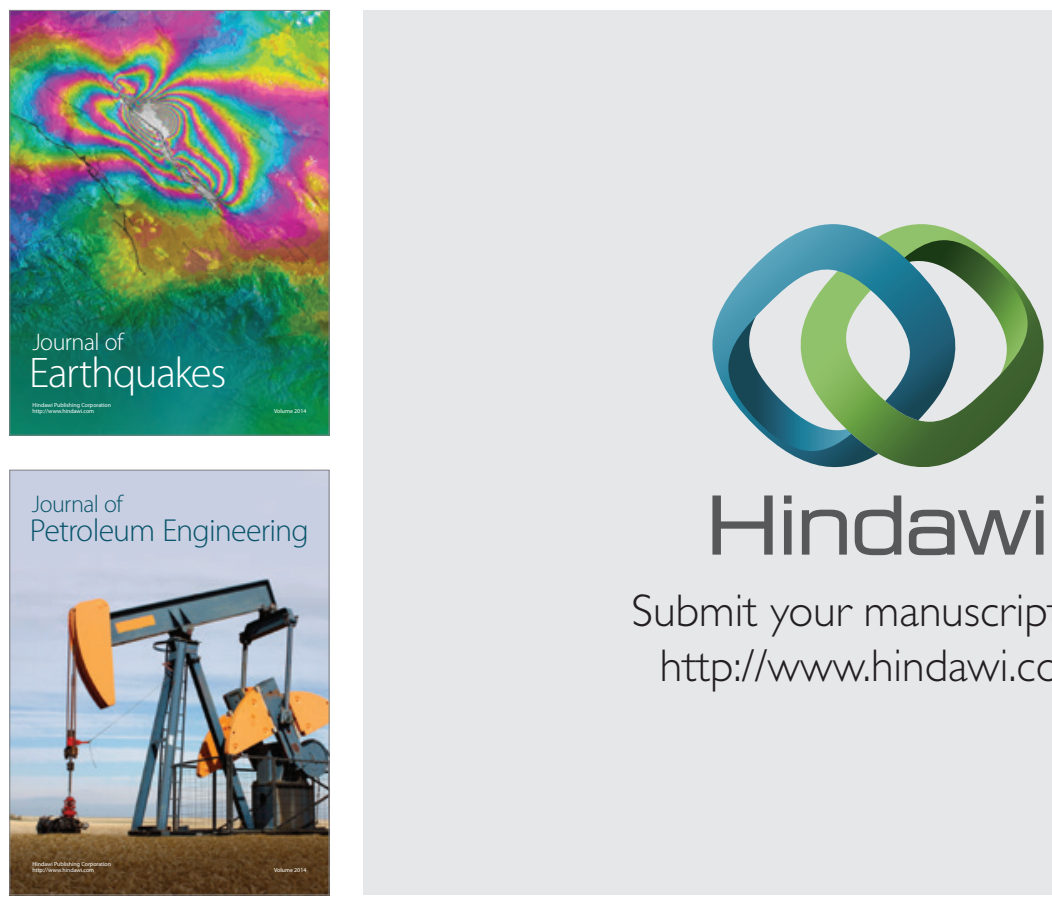

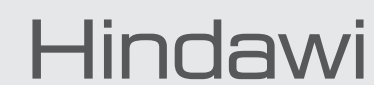

Submit your manuscripts at

http://www.hindawi.com
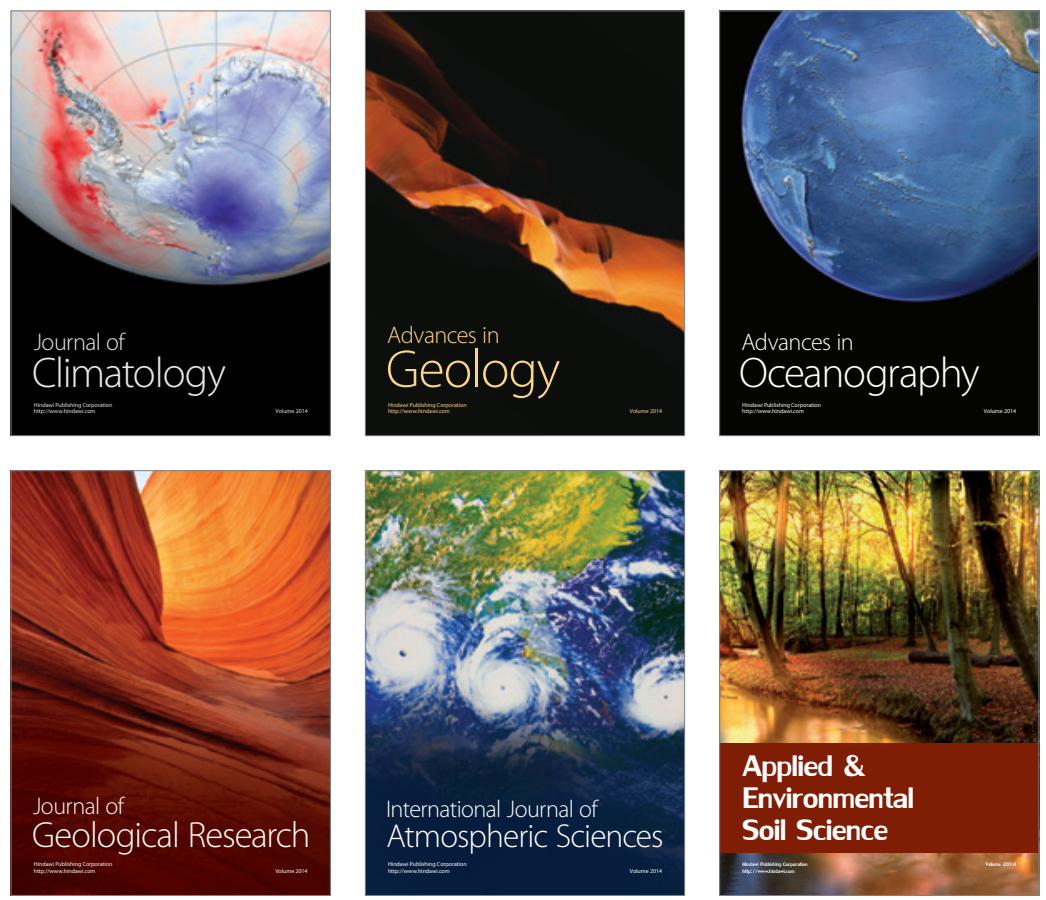
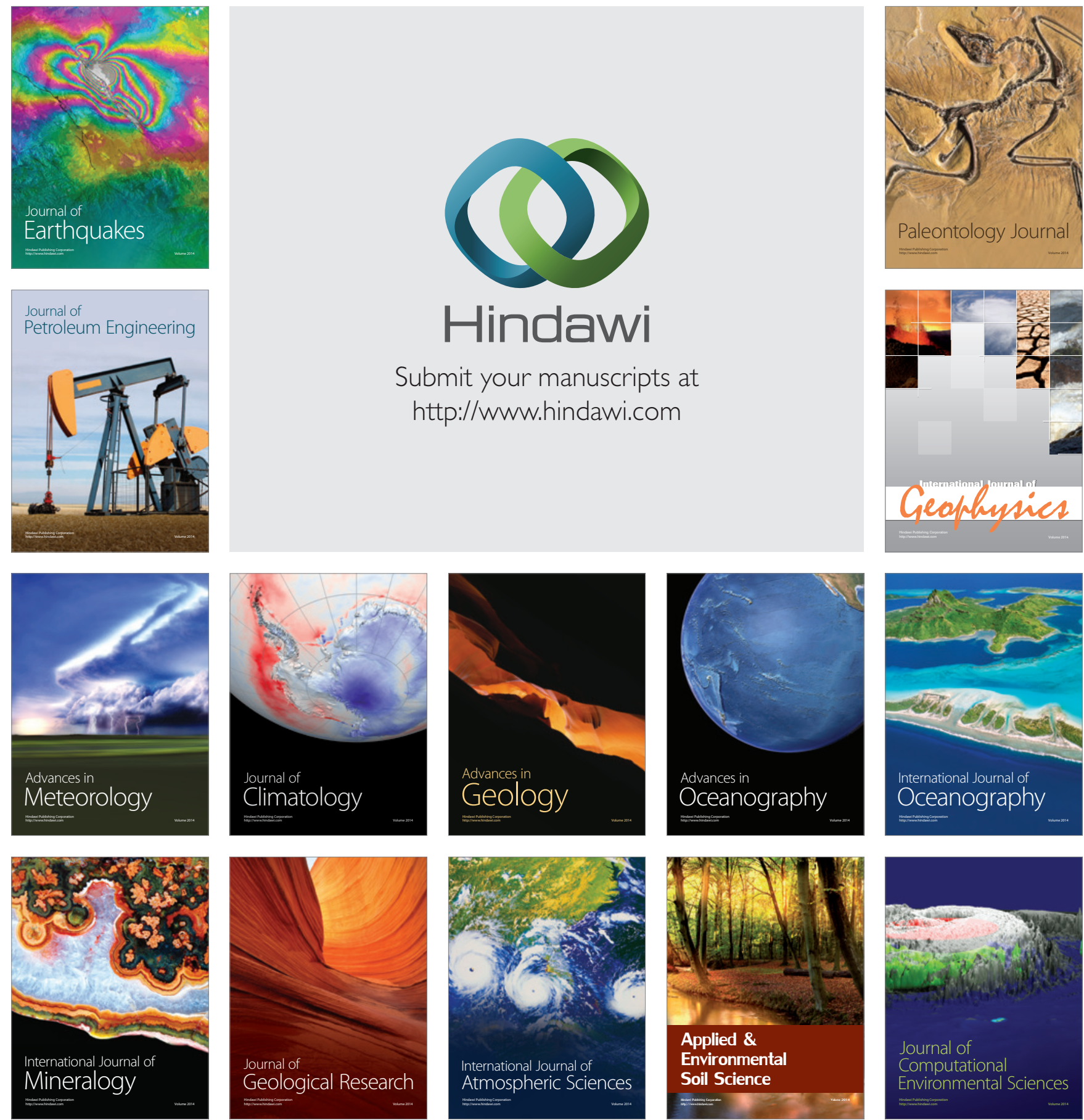